\title{
Similarities in effects of barbiturates and mild tranquilizers on activity in mice
}

\author{
LOUIS S. HARRIS, JACK PEARL AND MARIO D. ACETO \\ STERLING-WINTHROP RESEARCH INSTITUTE
}

To determine the extent of similarity in the effects of barbiturates and mild tranquilizers on motor activity, mice were given pentobarbital, phenobarbital, meprobamate, and chlormezanone over a wide range of doses. All drugs increased spontaneous motor activity in photocell units at low doses and decreased activity at higher doses. The drugs resembled each other in producing the same pattern of motor impairment. Ataxia was noted at intermediate doses, and impairment of the righting reflex and plosis were noted at higher doses. Mention was made of the possible relationship of motor impairment to changes in spontaneous activity and to changes in performance with different schedules of reinforcement.

That meprobamate and barbiturates have many similar effects in man has been stressed by Domino (1962, 1963). Additional similarities in their effects have been found in animals, inasmuch as meprobamate, pentobarbital, and phenobarbital increase the rates of responding in various tests at low doses and decrease the rates at higher doses (Dews, 1955; Ferster, Appel, \& Hiss, 1962; Geller \& Seifter, 1960, 1962; Kelleher \& Cook, 1959; Kelleher, Fry, Deegan, \& Cook, 1961; Waller \& Morse, 1963; Weissman, 1959). Of particular relevance to the present study, meprobamate and phenobarbital increased spontaneous motor activity in mice at low doses and decreased activity at higher doses (Chen \& Bohner, 1960; Gray, Osterberg, \& Rauh, 1961; Kinnard \& Carr, 1957). But much extrapolation is necessary to draw any conclusions from the animal work because the range of doses has been narrow, because only one drug was used, or because only slight changes in behavior were observed. Indeed, Berger (1963) has stressed the differences between meprobamate and barbiturates rather than the similarities.

To determine the extent of correspondence between the effects of two barbiturates, pentobarbital and phenobarbital, and two mild tranquilizers, meprobamate and chlormezanone, over a wide range of doses in mice, spontaneous motor activity was measured in photocell units (for chlormezanone see Siegler, 1962; Surrey \& Conrad, 1962).

\section{Method}

Male albino mice (ICR) weighed 18-24 gmat the start of testing in the 12 photocell cages. Each cage, discshaped, 3-3/4 in. high and 16 in. in diameter, had metal sides, wire mesh floors, and plastic ceilings. In ambulating from one half of the cage to the other, the mice broke the beam from an Autotron photocell unit, the only source of illumination in the experi- mental chamber. The photocell interruptions were recorded for two consecutive 15-min.periods on impulse counters outside the experimental chamber.

Thirty min. before the start of testing the mice were orally medicated at a volume of $1 \mathrm{cc} / 0.1 \mathrm{~kg}$ with either drugs suspended in 1\% gum tragacanth or a suspension of $1 \%$ gum tragacanth (control vehicle) and then were detained in cages which were similar to their living quarters. At the start of testing four mice that had received the same agent were put in each photocell cage. There were a total of four replications (16 mice, $\mathrm{N}=4$ ) for each dose and 14 for the control vehicle (56 mice, $\mathrm{N}=14$ ). Doses in $\mathrm{mg} / \mathrm{kg}$ follow: pentobarbital sodium at $30,45,90,135,150$; phenobarbital sodium at $25,50,75,150,200,300,500$; meprobamate at $62.5,125,250,500,600$; chlormezanone at $50,100,200,300,400,500$. The mice were observed for signs of motor impairment 30,45 , and $60 \mathrm{~min}$. after medication.

\section{Results and Discussion}

Figure 1 shows the mean number of photocell interruptions on the arithmetic scale and the doses on the logarithmic scale. With increases in doses of all drugs, activity increased to values above the control level and then decreased to doses below the control level. According to the Mann-Whitney $U$ test the spontaneous motor activity of the control group was significantly different (ps< .01) from the drug groups at the following doses $(\mathrm{mg} / \mathrm{kg})$ : pentobarbital sodium, 30, 45, 90, 135, 150; phenobarbital sodium, 50,75, 150, 200, 500; meprobamate, 250, 600; chlormezanone, 50, 100, 200, 500. It should be noted that the curves for the two barbiturates were like those of the two tranquilizers. Mention

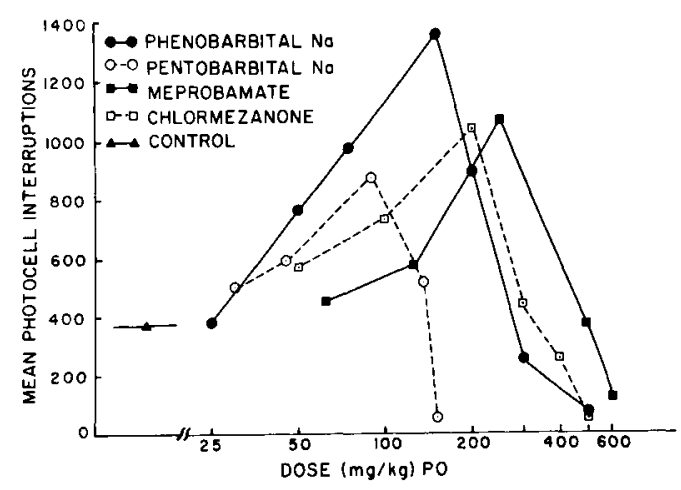

Fig. 1. Spontaneous motor activity as a function of dose. 
has already been made in the introduction section that pentobarbital, phenobarbital, anci meprobamate seem to increase activity at relatively low doses and decrease activity at higher doses in various test situations. The central nervous system stimulants like amphetamine also exhibit this biphasic action. Thus, low doses of amphetamine increase spontaneous activity, while large doses decrease activity.

Possibly related to changes in activity were motor effects such as ataxia, impairment of the righting reflex, and ptosis (see Table 1). Ataxia was noted at intermediate doses at which the mice were relatively active in the photocell units, whereas impairment of the righting reflex and ptosis were noted at higher doses at which the mice were much less active. With the psychomotor stimulants such as amphetamine the marked increases in spontaneous activity are not accompanied by ataxia or other motor deficits. Impairment of motor reflexes may also affect the results of tests in which the task or schedule of reinforcement has been varied. One should be cautious in attributing performance changes to variations in tasks per se before one excludes the possibility that the performance changes reflect differences in the capacity of drugged animals to make various responses.

Table 1. Doses Producing Impairment of Motor Reflexes

\begin{tabular}{lccl} 
Drugs & Ataxia & Impaired Righting & Ptosis \\
\hline Pentobarbital Na & 90 & 135,150 & 150 \\
Phenobarbital Na & 200 & 300,500 & 500 \\
Meprobamate & 250,500 & 600 & 600 \\
Chlormezanone 200,300,400 & 400,500 & 500 \\
\hline
\end{tabular}

\section{References}

Berger, F. M. The similarities and differences between meprobamate and barbiturates. Clin. Pharmacol. Ther., 1963, 4, 209-231.
Chen, G., \& Bohner, Barbara. A study of certain CNS depressants. Arch. int. Pharmacodyn. Ther., 1960, 125, 1-20.

Dews, P. B. Studies on behavior. I. Differential sensitivity to pentobarbital of pecking performance in pigeons depending en the schedule of reward. J. Pharmacol. exp. Ther., 1955, 113. 393-401.

Domino, E. F. Human pharmacology of tranquilizing drugs. Clin. Pharmacol. Ther., 1962, 3, 599-664.

Domino, E. F. Commentary on Berger, F. M. The similarities and differences between meprobamate and barbiturates. Clin. Pharmacol. Ther, 1963, 4, 231-233.

Ferster, C. B., Appel, J. B., \& Hiss, R. A. The effects of drugs on a fixed ratio performance suppressed by a pre-time-out stimulus. J. exp. Anal. Behav., 1962, 5, 73-88.

Geller, I., \& Seifter, J. The effects of meprobamate, barbiturates, d-amphetamine and promazine on experimentally induced conflict in the rat. Psychopharmacologia, Berlin, 1960, 1, 482-492.

Geller, I., \& Seifter, J. The effects of mono-urethanes, di-urethanes and barbiturates on a punishment discrimination. $J$. Pharmacol. exp. Ther., 1962, 136, 284-288.

Gray, W. D., Osterberg, A. C., \& Rauh, C. E. Neuropharmacological actions of mephenoxalone. Arch. int. Pharmacodyn. Thcr., $1961,134,198-215$.

Kelleher, R. T. \& Cook, L. Effects of d-amphetamine, meprobamate, phenobarbital, methenesin, or chlorpromazine on DRL and and FR schedules of reinforcement with rats. J. exp. Anal. Behav., 1959, 2, 267.

Kelleher, R. T., Fry, W., Deegan, J., \& Cook, L. Effects of meprobamate on operant behavior in rats. $J$. Pharmacol exp. Ther. $1961,133,271-280$.

Kinnard, W. J. Jr., \& Carr, C. J. A preliminary procedure for the evaluation of central nervous system depressants. J. Pharmacol. exp. Ther., 1957, 121, 354-361.

Siegler, P. E. Clinical use of chlormezanone. In J. H. Nodine \& J. H. Moyer (Eds.), Psychosomatic medicine. Philadelphia, Pa.: Lea \& Febiger, 1962 . Pp. 531-536.

Surrey, A. R., \& Conrad, E. A. Pharmacodynamics of chlormezanone. In J. H. Nodine \& J. H. Moyer (Eds.), Psychosomatic medicine. Philadelphia, Pa.: Lea \& Febiger, 1962. Pp. 523-530.

Waller, M. B., \& Morse, W. H. Effects of pentobarbital on fixedratio reinforcement. J. exp. Anal. Behav., 1963, 6, 125-130.

Weissman, A. Differential drug effects upon a three-ply multiple schedule of reinforcement. J. exp. Anal. Behar., 1959, 2, 271287 . 